\title{
Assessment of Maternal and Perinatal Morbidity and Mortality in Eclampsia by Early Termination of Pregnancy in Bangladesh
}

\author{
Dr. Sabrin Farhad ${ }^{1 *}$, Dr. Shamima Haque Chowdhury ${ }^{2}$, Dr. Farjana Islam ${ }^{3}$, Dr. Taposhi Rabeya ${ }^{4}$, Dr. Salima Akter ${ }^{5}$ \\ ${ }^{1}$ Assistant Professor, Department of Gynecology \& Obstetrics, Uttara Adhunik Medical College and Hospital, Dhaka, Bangladesh \\ ${ }^{2}$ Professor \& Head of Department, Department of Gynecology \& Obstetrics, Uttara Adhunik Medical College and Hospital, Dhaka, Bangladesh \\ ${ }^{3}$ Registrar, Department of Gynecology \& Obstetrics, Uttara Adhunik Medical College and Hospital, Dhaka, Bangladesh \\ ${ }^{4}$ Medical Officer, Department of Gynecology \& Obstetrics, Uttara Adhunik Medical College and Hospital, Dhaka, Bangladesh \\ ${ }^{5}$ Assistant Registrar, Department of Gynecology \& Obstetrics, Uttara Adhunik Medical College and Hospital, Dhaka, Bangladesh
}

DOI: $10.36348 /$ sijog.2021.v04i02.003

| Received: 21.01.2021 | Accepted: 06.02.2021 | Published: 17.02.2021

*Corresponding author: Dr. Sabrin Farhad

\section{Abstract}

Background: Eclampsia is commonly defined as new onset of grand mal seizure activity and/or unexplained coma during pregnancy or postpartum in a woman with signs or symptoms of pre-eclampsia. Objective: The objective of this study was to assess the maternal and perinatal morbidity and mortality in eclampsia by early termination of pregnancy. Methodology and Materials: It was a descriptive observational study conducted in the Department of Gynecology \& Obstetrics, Uttara Adhunik Medical College and Hospital, Dhaka, Bangladesh during the period from January 2017 to December 2019. In total 188 pregnant women admitted to the mentioned hospital with antepartum eclampsia were finalized as the study population. This study was approved by the ethical committee of the same hospital. Between the age group, maternal and perinatal outcomes were compared. Data were analyzed using statistical methods with SPSS version 22. Results: In this study $7(9.86 \%)$ maternal deaths had occurred among 71 vaginal deliveries. 6(5.36\%) maternal deaths had occurred among 112 caesarean deliveries. Besides these, 5 cases were undelivered which all were maternal death. Among 188 cases total of 18(9.57\%) maternal deaths had occurred. We did not find any significant correlation between the total number and modes of deliveries of maternal deaths $(\mathrm{P}=0.581)$. Among 71 vaginal deliveries, $10(14.08 \%)$ stillbirths and $28(39.44 \%)$ neonatal deaths occurred respectively; that is why in total $38(53.52 \%)$ perinatal deaths occurred against total 71 vaginal deliveries. Among 112 caesarean deliveries, 3(2.68\%) stillbirths and $10(8.93 \%)$ neonatal deaths occurred respectively; that is why in total 13(11.61\%) perinatal deaths occurred against total 112 caesarean deliveries. Besides these, perinatal deaths were counted as stillbirths which were 5 in number. In this study in total 56(29.79\%) perinatal deaths occurred of total study people. Conclusion: In pregnant women with eclampsia frequency of caesarian delivery is near about two times than vaginal delivery. But the maternal mortality in caesarian delivery of pregnant women with eclampsia is near about half of that in vaginal delivery. In such cases, perinatal mortality is about one-fifth in caesarian delivery than that of vaginal delivery.

Keywords: Eclampsia, maternal mortality, perinatal morbidity, pregnancy.

Copyright () 2021 The Author(s): This is an open-access article distributed under the terms of the Creative Commons Attribution 4.0 International License (CC BY-NC 4.0) which permits unrestricted use, distribution, and reproduction in any medium for non-commercial use provided the original author and source are credited.

\section{INTRODUCTION}

Eclampsia is considered a complication of severe preeclampsia, usually defined as new onset of grand mal seizure activity and/or unexplained coma during pregnancy or postpartum in a woman with signs or symptoms of pre-eclampsia [1, 2]. It is a life threatening emergency that continues to be a major cause of serious maternal and perinatal morbidity and mortality. Basically, preeclampsia and eclampsia are major causes of maternal and perinatal morbidity and mortality. In the developing countries, Eclampsia is one of the most common causes of maternal mortality [3]. For improving the maternal and perinatal complications in Eclampsia, Early termination of pregnancy remains the definitive treatment [4]. Around 10\% of pregnant women are affected by hypertensive disorders of pregnancy globally comprising of pre-eclampsia and eclampsia, gestational hypertension and chronic hypertension [3]. In Bangladesh, the incidence of preeclampsia is very high. It is about $10 \%$ to $15 \%$ of all deliveries [6]. It is higher compared to developed countries. In a study, the incidence of eclampsia in India was also found to be around $1.56 \%$ [7]. The 
Sabrin Farhad et al; Sch Int J Obstet Gynec, Feb. 2021; 4(2): 35-40

world-wide incidence of preeclampsia is still high in spite of the significant improvement of the maternal and child care over the last decades. All over the world preeclampsia is the 3rd leading cause for maternal mortality and the 7 th leading cause for the perinatal mortality [8]. In Bangladesh only $49 \%$ of women of total population is under antenatal care and only $30 \%$ women are aware of pregnancy complication during pregnancy. $13 \%$ women end their pregnancies under medical supervision and the rest of them have delivery assistance from TBA, relatives and friends or no access to obstetric care [9]. Only $29 \%$ of women get treatment for complication from medically trained provider [10]. For this reason, most preeclampsia cases remain unrecognized until severe complication such as eclampsia occurs. On the other hand, preeclampsia is the leading cause of premature termination of pregnancy, and so as intrauterine growth retardation, perinatal mortality and morbidity. Eclampsia is a preventable disease if preeclampsia is detected and treated at an early stage [11]. Good antenatal care can prevent the occurrence of eclampsia. Goals of the treatment of eclampsia are to stop and prevent seizure to control high blood pressure and prompt delivery of the baby [12].

\section{OBJECTIVES}

\section{General Objective}

- To assess the maternal and perinatal morbidity and mortality in eclampsia by early termination of pregnancy.

\section{Specific Objective}

- To collect information regarding maternal mortality and morbidity in eclampsia by early termination of pregnancy.

- To collect information regarding perinatal mortality and morbidity in eclampsia by early termination of pregnancy.

\section{METHODOLOGY \& MATERIALS}

This was a descriptive observational study which was conducted in the Department of Gynecology \& Obstetrics, Uttara Adhunik Medical College and Hospital, Dhaka, Bangladesh during the period from January 2017 to December 2019. In total 188 pregnant women admitted to the mentioned hospital with antepartum eclampsia were finalized as the study population. This study was approved by the ethical committee of the same hospital. Between the patient groups, maternal and perinatal outcomes were compared. In this study, convenient sampling was used. All the pregnant women presenting with eclampsia irrespective of the booking status were included in the study. All the pregnant women presenting with eclampsia with a gestational age of less than 28 weeks were excluded from the study. After getting informed consent and ethical approval, the patients were recruited into the study. The patients were closely monitored and treated during their stay in the hospital. Maternal and perinatal outcomes were analyzed. Data were recorded in a pretested proforma and then entered in Microsoft Excel and analysis was carried out with IBM SPSS version 22. $\mathrm{p}<0.05$ was considered statistically significant. Maternal and perinatal mortality was the primary outcome variable. The explanatory variables included mode of delivery and time taken for termination of pregnancy.

\section{RESULTS}

In this study, more than $50 \% \quad(52.13 \%)$ respondents were from 10-35 years' age group. Then $34.57 \%$ were from $<35$ years' age group and the rest $13.30 \%$ were from $<20$ years' age group. In analyzing the parity of the participants we found, among all the participants the highest $(46.81 \%)$ number of participants were with primipara. Then $42 \%$ were with 2 to 4 para and the rest $11.17 \%$ of participants were with more than 5 parties. In this study, the highest number of participants had caesarean delivery which was in $59.57 \%$. Then $37.77 \%$ had a vaginal delivery and the rest $2.66 \%$ of participants remained undelivered. In this study in analyzing the maternal mortality, we observed, in 71 cases of vaginal delivery 7 maternal death had been occurred which was $9.86 \%$ among 71 cases. On the other hand, in 112 cases of caesarean delivery 6 maternal death had been occurred which was $5.36 \%$ among 112 cases. Besides these, 5 cases were undelivered and all undelivered cases turned to maternal death. In this current study among total 188 cases, in total 18 maternal deaths had been occurred which was $9.57 \%$ against the total cases of this study. We did not find a significant correlation between the total number of cases and maternal deaths in modes of delivery where the P-value was 0.581 . In analyzing the maternal morbidity among 188 participants, we found Cerebrovascular hemorrhage/disorders was comparatively highest, which was $8(4.26 \%)$, followed by Peripartum cardiomyopathy, Amniotic fluid embolism and Venous thromboembolism were 3(1.6\%), Uterine rupture $2(1.06 \%)$ and finally Intrauterine fetal demise was $1(0.53 \%)$. Regarding the perinatal mortality, we observed among 71 vaginal deliveries 10 stillbirths occurred which was $14.08 \%, 28$ neonatal deaths occurred which was $39.44 \%$; that is why in total 38 perinatal deaths occurred which was $53.52 \%$ against total 71 vaginal deliveries. On the other hand, among 112 caesarean deliveries 3 stillbirths occurred which was $2.68 \%, 10$ neonatal deaths were occurred which was $8.93 \%$; that is why in total 13 perinatal deaths occurred which was $11.61 \%$ against total 112 caesarean deliveries. Besides these, perinatal deaths were counted as stillbirths which were 5 in number. So in this study in total 56 perinatal deaths were occurred which was $29.79 \%$ among total study people. There had not been any twin birth in this intervention. 
Table-1: General characteristics of participants $(\mathbf{N}=188)$

\begin{tabular}{|l|l|l|}
\hline Characteristics & $\mathrm{n}$ & $\%$ \\
\hline Age group (years) & 25 & 13.30 \\
\hline Age <20 & 98 & 52.13 \\
\hline $20-35$ & 65 & 34.57 \\
\hline$>35$ & 79 & 42.02 \\
\hline Parity & 88 & 46.81 \\
\hline Primipara & 81 & 11.17 \\
\hline Para 2-4 & 21 \\
\hline Parity 5 or higher & 71 & 37.77 \\
\hline Mode of delivery & 112 & 59.57 \\
\hline Vaginal & 5 & 2.66 \\
\hline Caesarean delivery & 5 \\
\hline Undelivered &
\end{tabular}

\section{Patients Age Groups}

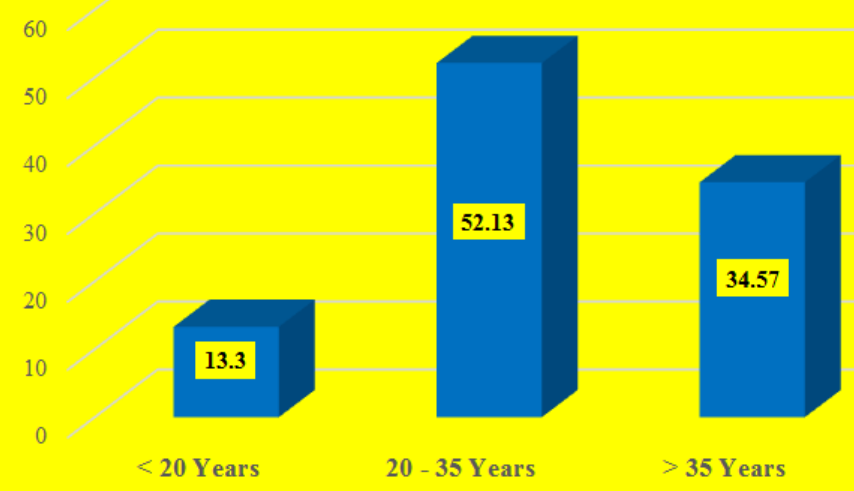

Fig-1: Patients Age Group Distribution

Table-2: Maternal mortality among participants $(\mathrm{N}=188)$

\begin{tabular}{|l|l|l|l|l|}
\hline Mode of delivery & Total Number (n) & Death (n) & \% & P Value \\
\hline Vaginal & 71 & 7 & 9.86 & \multirow{2}{*}{0.581} \\
\cline { 1 - 4 } Caesarean & 112 & 6 & 5.36 & \\
\cline { 1 - 2 } Undelivered & 5 & 5 & 100.0 & \\
\hline Base & 188 & 18 & 9.57 & \\
\hline
\end{tabular}

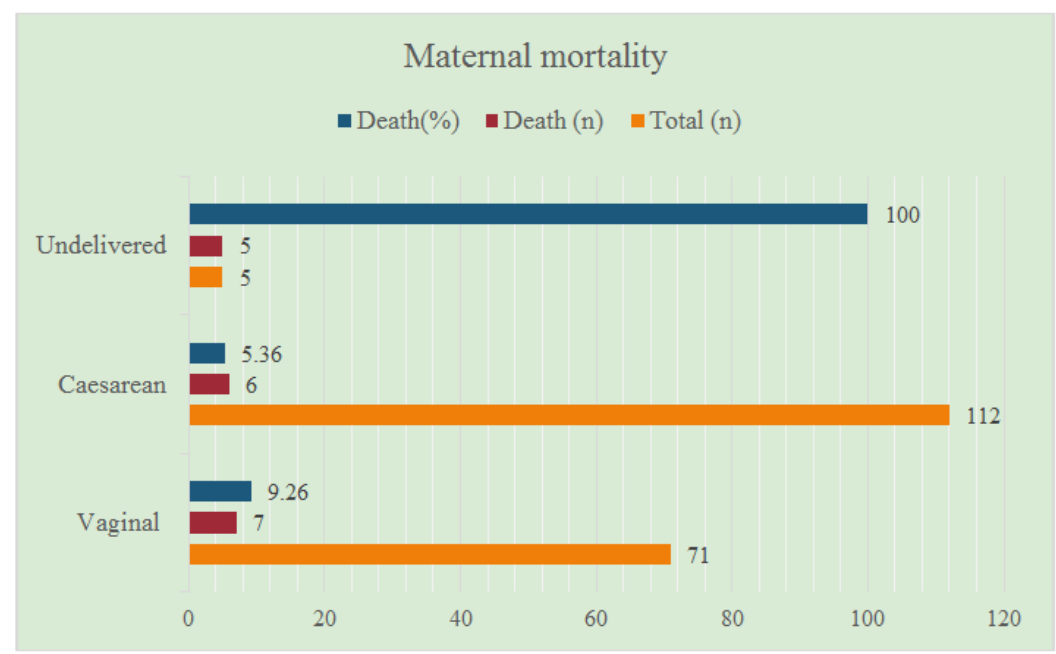

Fig-2: Maternal mortality of patients 
Sabrin Farhad et al; Sch Int J Obstet Gynec, Feb. 2021; 4(2): 35-40

Table-3: Maternal Morbidity among participants $(\mathrm{N}=188)$

\begin{tabular}{|l|l|l|}
\hline Maternal Morbidity & $\mathbf{n}$ & $\mathbf{\%}$ \\
\hline Cerebrovascular hemorrhage/disorders & 8 & 4.26 \\
\hline Peripartum cardiomyopathy & 3 & 1.6 \\
\hline Amniotic fluid embolism & 3 & 1.6 \\
\hline Venous thromboembolism & 3 & 1.6 \\
\hline Uterine rupture & 2 & 1.06 \\
\hline Intrauterine fetal demise & 1 & 0.53 \\
\hline
\end{tabular}

Table-4: Perinatal mortality in intervention $(\mathrm{N}=188)$

\begin{tabular}{|l|l|l|l|l|l|l|l|}
\hline \multirow{2}{*}{ Mode of delivery } & Case (n) & \multicolumn{2}{|l|}{ Still birth } & \multicolumn{2}{l|}{ Neonatal death } & \multicolumn{2}{l|}{ Perinatal death } \\
\cline { 2 - 8 } & & $\mathbf{n}$ & $\mathbf{\%}$ & $\mathbf{n}$ & $\mathbf{\%}$ & $\mathbf{n}$ & \% \\
\hline Vaginal & 71 & 10 & 14.08 & 28 & 39.44 & 38 & 53.52 \\
\hline Caesarean & 112 & 3 & 2.68 & 10 & 8.93 & 13 & 11.61 \\
\hline Undelivered & 5 & 5 & 100.0 & 0 & 0.00 & 5 & 100.0 \\
\hline Base & 188 & 18 & 9.57 & 38 & 20.21 & 56 & 29.79 \\
\hline
\end{tabular}

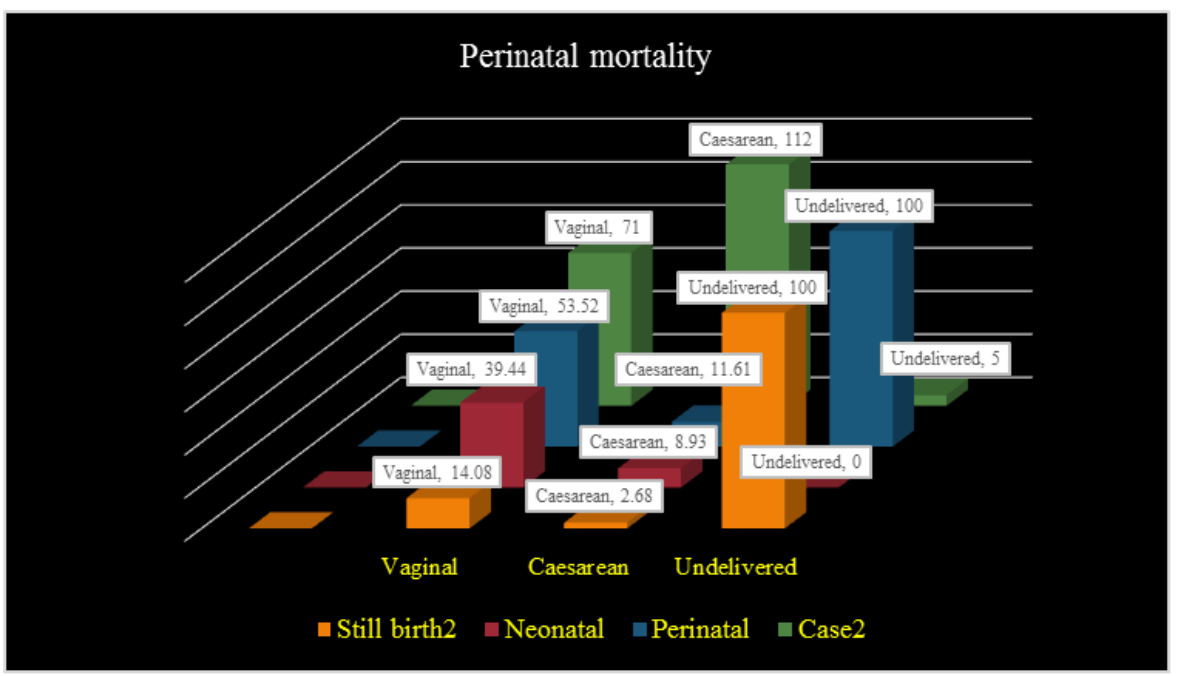

Fig-3: Perinatal mortality of patients

\section{DISCUSSION}

The aim of this study was to assess the maternal and perinatal morbidity and mortality in eclampsia by early termination of pregnancy. In this study among total 188 subjects, caesarean delivery was done in majority of the cases which was in $59.57 \%$. On the other hand, $37.77 \%$ underwent vaginal delivery while $2.66 \%$ died before delivering the baby. A similar study done in a tertiary care hospital in Andhra Pradesh from February 2015 to 2016, observed that the vaginal delivery was done in $56 \%$ of the cases while $44 \%$ required caesarean section [13]. They observed the incidence of eclampsia was $0.58 \%$ in the hospital in 8595 deliveries [13]. They concluded that eclampsia alone is not an indication for caesarean section and also observed that mode of delivery had no significant effect on the outcome of the eclamptic [13]. In our study, maternal mortality was higher in in those undergoing vaginal delivery $(9.86 \%)$ in comparison to the caesarean section group $(5.36 \%)$. There were 14 perinatal deaths in eclampsia patients, giving a perinatal mortality rate of $280 / 1000$ in the study done by study Shaikh et al., [13]. In analyzing the perinatal mortality we observed, among 71 vaginal deliveries 10 still births were occurred which was $14.08 \%, 28$ neonatal deaths were occurred which was $39.44 \%$; that is why in total 38 perinatal deaths were occurred which was $53.52 \%$ against total 71 vaginal deliveries. On the other hand, among 112 caesarean deliveries 3 still births were occurred which was $2.68 \%, 10$ neonatal deaths were occurred which was $8.93 \%$; that is why in total 13 perinatal deaths were occurred which was $11.61 \%$ against total 112 caesarean deliveries. Besides these, perinatal deaths were counted as still births which was 5 in number. So in this study in total 56 perinatal deaths were occurred which was $29.79 \%$ among total study people. In our study, perinatal mortality was higher in vaginal delivery group $(53.52 \%)$ while caesarean section group suffered less perinatal losses (11.61\%). In another study, the perinatal mortality was 132 per 1000 [14]. In a retrospective hospital based study done in India, total percentage of perinatal deaths due to eclampsia was $14.6 \%$ and still birth were $10.6 \%, 32 \%$ of babies have NICU admission [15]. Stillbirth rate was $22.5 \%$ in women presenting with eclampsia in another. In the present study, most of the patients underwent 
Sabrin Farhad et al; Sch Int J Obstet Gynec, Feb. 2021; 4(2): 35-40

caesarean section within 4 hours of admission, whereas majority of patients of vaginal delivery were delivered after 4 hours of admission. There was a statistically significant difference between the groups in the proportion of maternal deliveries between 1 to 4 hours of admission $(\mathrm{p}=0.017)$ and 4 to 12 hours of admission $(\mathrm{p}=0.034)$. Almost $83.3 \%$ presented within 12 hours of the onset of the fits and nearly half $(44.9 \%)$ had their convulsion before the onset of labor, in the study by Yakasai et al., [14]. A prospective study conducted at the maternity unit of a tertiary teaching hospital observed the incidence of eclampsia to be $2.8 \%$ among 7,558 deliveries [16]. The mortality rate was $19.4 \%$ in their study while it was $9 \%$ in our study [16]. The duration from admission to delivery did not significantly influence mortality in their study [16]. But they observed vaginal delivery was found to be significantly associated with mortality compared with cesarean section (crude odds ratio $=2.55 ; 95 \% \mathrm{CI}=1.11-$ 5.87; $\mathrm{p}=0.0272$ ) and arrival at our hospital 12 hours or more after the onset of seizures increased the risk of maternal death about 22-fold [16]. Tukur et al., in their study in Nigeria observed that delay in hospital admission was significantly associated with mortality in subjects with eclampsia [17]. Hussain F et al., in their study in Dhaka observed that mortality was higher in subjects with eclampsia admitted $>5$ hours after the onset of seizures [18]. In a hospital based retrospective study done in a tertiary care center in rural parts of eastern India, majority $(73.9 \%)$ of deaths due to eclampsia occurred within the first 12 hours of admission [19]. 82\% patient delivered within 10 hours of admission in another study [15]. The decision to perform cesarean section should be based on fetal gestational age, fetal condition and presence of associated obstetric indications (mal presentations or the other high-risk factors), cervical bishop score and maternal condition but not merely by the presence of eclampsia [17]. Considering all of these we can claim that, to reduce maternal and perinatal mortality and morbidity caesarian delivery may be better choice than vaginal delivery for pregnant women with eclampsia.

\section{CONCLUSION AND RECOMMENDATIONS}

In pregnant women with eclampsia frequency of caesarian delivery is near about two times than vaginal delivery. But the maternal mortality in caesarian delivery of pregnant women with eclampsia is near about half of that in vaginal delivery. In such cases perinatal mortality is about one fifth in caesarian delivery than that of vaginal delivery. So to reduce maternal and perinatal mortality and morbidity caesarian delivery may be better choice than vaginal delivery for pregnant women with eclampsia. This was a single centered study with a limited sample size. The findings of this study may not replicate the exact state of the whole country. So, for getting more specific result we would like to recommend for conducting similar more studies in several places with larger sample size.

\section{REFERENCES}

1. Mattar, F., \& Sibai, B. M. (2000). Eclampsia. VIII. Risk factors for maternal morbidity. Am J Obstet Gynecol, 182(2):307-12.

2. Warrington, J. P. (2015). Placental ischemia increases seizure susceptibility and cerebrospinal fluid cytokines. Physiol Rep. 3(11).

3. World Health Organization. Trends in maternal mortality: 1990 to 2015. Available at: http://www.who.int/ reproductive health /publications/ monitoring/maternal-mortality2015/en/. Accessed on 10 May 2020.

4. WHO Recommendations for prevention and treatment of pre-eclampsia and eclampsia. Available from: https://www.ncbi.nlm.nih.gov/books/NBK 140563/. Accessed on 10 May 2020.

5. Duley, L. (2009, June). The global impact of preeclampsia and eclampsia. In Seminars in perinatology (Vol. 33, No. 3, pp. 130-137). WB Saunders.

6. Hall, D. R., Odendaal, H. J., Steyn, D. W., \& Grove, D. (2000). Expectant management of early onset, severe pre- eclampsia: maternal outcome. BJOG: An International Journal of Obstetrics \& Gynaecology, 107(10), 1252-1257.

7. Swain, S., Ojha, K. N., Prakash, A., \& Bhatia, B. D. (1993). Maternal and perinatal mortality due to eclampsia. Indian pediatrics, 30, 771-771.

8. Dekker, G. A., \& Sibai, B. M. (1991). Early detection of preeclampsia. American journal of obstetrics and gynecology, 165(1), 160-172.

9. Robers, J. M., \& Redman, C. W. G. (1993). Preeclampsia: more than pregnancy induced hypertension. Lancet, 341, 1447-51.

10. Statistics from The State of the World's Children 2007, BDHS and MICS.

11. Redman, C. W. G., Roberts, J. M. (1993). Management of preeclampsia. Lancet, 341, 1451-54.

12. Magpie Trial Follow- Up Study Collaborative Group. (2007). The Magpie Trial: a randomised trial comparing magnesium sulphate with placebo for pre- eclampsia. Outcome for women at 2 years. BJOG: An International Journal of Obstetrics \& Gynaecology, 114(3), 300-309.

13. Begum, S. S. A study on maternal and perinatal out comes in cases of eclampsia admitting to government medical college and general hospital, Anantapuramu, Andhra Pradesh, India. International Journal of Reproduction, Contraception, Obstetrics and Gynecology, 5(7), 2147-50.

14. Yakasai, I. A., \& Gaya, S. A. (2011). Maternal and fetal outcome in patients with eclampsia at Murtala Muhammad specialist Hospital Kano, Nigeria. Annals of African medicine, 10(4), 305309.

15. Kurude, V. N., Kokate, P. H., Saha, D., \& Jha, E. K. (2017). Study of maternal and perinatal 
outcome in eclampsia. Paripex Ind J Res, 6(4), 635.

16. Rabiu, K. A., Adewunmi, A. A., Ottun, T. A., Akinlusi, F. M., Adebanjo, A. A., \& Alausa, T. G. (2018). Risk factors for maternal mortality associated with eclampsia presenting at a Nigerian tertiary hospital. International journal of women's health, 10, 715-721.

17. Tukur, J., \& Muhammad, Z. (2010). Management of eclampsia at AKTH: before and after magnesium sulphate. Nigerian Journal of Medicine, 19(1), 104-147.

18. Hussain, RB Johanson, P. Jones, F. (2000). One year survey of maternal mortality associated with eclampsia in Dhaka Medical College Hospital. Journal of Obstetrics and Gynaecology, 20(3), 239-241.

19. Das, R., \& Biswas, S. (2015). Eclapmsia: The major cause of maternal mortality in Eastern India. Ethiopian journal of health sciences, 25(2), 111-116. 